\title{
Discussion on the Personnel Training of University Libraries
}

\author{
Hong bing Shen \\ Jianghan University library \\ Wuhan , China \\ shb720725@163.com
}

\begin{abstract}
Talents have been the cornerstone of the construction and development of libraries. This essay is aimed at analyzing the present situation of the personnel training of university libraries and exploring new approaches of personnel training, in a bid of constituting a high-leveled, well-balanced interdisciplinary talent pool and promoting the sustainable development of libraries.
\end{abstract}

Keywords-university library; personnel training; construction

\section{INTRODUCTION}

In celebration of the 90th anniversary of the CPC Founding Conference, General Secretary of Communist Party $\mathrm{Hu}$ Jintao put talent problem to a highly important position in his speech. Whether socialist road with Chinese characteristics can be broader and broader, whether our Chinese nation can achieve the great rejuvenation, are depending on whether a large number of talented people can be cultivated continuously, furthermore are relying on our discovering the talents and let their talent fully displayed. This remark is enlightening, meaningful and set us thinking. Along with the high-speed development of globalization, the original library management system and service pattern is experiencing great changes. Books and periodicals-based information services are being taken place by knowledge service based on information communication. At this very moment of reform, talent problem becomes noticeable among colleges and universities, where the major concern is the stale knowledge structure of library personnel, uneven professional standards, lack of talents and brain drain. Especially, the urgent priority is the shortage of high-leveled talents. It's impending to build a talent team which is of high-quality and adaptive to the era development[1].

\section{SignificANCE OF TALENT POOL IN LibRARY}

\section{A. Talent pool of library is a tendency in its undertakings}

Nowadays the main stream of the world is knowledgebased economy and digitization. All trades and professions are becoming digitized; libraries are no exception to the rule. Firstly, the development of library digitization is more and more quickly. Ever since the U.S. started studying digital library, many countries throughout the world began their own researches and constructions in the following few decades and some sophisticated techniques in computer and telecommunication fields are being applied to the digital library field. The prospect for libraries is coexisting opportunities and challenges for itself and its staff. In the book, the knowledge navigation -- 21st Century Librarian's mission, the author Rory Chase said, for libraries and librarians, Knowledge-based Economy Age is a period full of changes and opportunities. With the rapid development of computer technologies and network capabilities, the coming of Knowledge-based Economy Age is an opportunity for staff working in libraries, but also an awesome challenge. The use of computer and library services based on computer network are more and more, thus for librarians in colleges and universities, not only is being familiar with business needed but computer operation. Based on this, libraries are in great need of outstanding talent pool in line with the progress of library undertakings[2].

\section{B. Library Talent Pool is to Meet the Needs of Library Operations Enhancement}

With the development of modern science and technology, library personnel free their energy from the trifles which enable them to engage themselves with more professional work, thus the transition from simply borrowing and returning books to deepened reference and consulting service. The intensiveness of globalization process and quick advancement of Internet make a radical change possible. The change is about the management system and service pattern. Information services based on books and periodicals are being replaced by knowledge service based on information communication. The modern libraries are more inclined to real-time network services.

In the past, collection and conservation of paper documents is a traditional function of library; in the future, the function will become smaller. University libraries for future is a knowledge, technology and intellectuality intensive department with great resource advantages, plus some inherent characteristics, for example, the extensiveness and sharing of resources, making future university libraries a place where education, culture and entertainment, and information dissemination are joint together. A high-quality talent pool is needed to carry out the new function in hope of increasing new professional work.

\section{Status QuO OF TALENT POOL IN UNIVERSITY LIBRARIES}

\section{A. Library Marginalization Results in Talents Role Weakening}

Currently, the Internet is developing at quite a high speed. Online resources flood in, readers have innumerable ways of 
getting information, accordingly, and university libraries are not the only choice for readers' access to gain information. In addition, university libraries are in the period of reform, where traditional libraries are transforming into electronic, digital, networking libraries. Functions of libraries in social environment are questioned. Library is not the first-line department in a university, as a supplementary department, compared with those core departments (e.g. Departments that carry out teaching and research work, academies or offices.) Library has a tendency of marginalization. The status and payment of library in colleges and universities are not paid enough attention to, talent pool in them are unable to realize their value and genius, which weakens function of the talents[3].

\section{B. Lack of Talent in University Libraries}

Due to the long-existing historical reasons, most staff in university libraries is not the matching major. Personnel return in other departments, the consequence of arranging wives of their doctor talents after universities bring them in. All these contribute to the uneven professionalism of library personnel. Another reason for the lack of talent is highleveled personnel is hard to bring in and also easy to lose. Universities have strict personnel establishment and academic threshold which makes it difficult to introduce talents. Also, the status, payment, and development question of libraries in colleges and universities are not attached enough importance to, the function is not recognized. What's more, the highly-educated people who are employed by libraries through hard and thin try their best to run away after working a while, which result in brain drain. The third reason is the radical change from traditional libraries to digitized and networked ones; there exist unprecedented width of big change, greater coverage of content and amazing speed. The continuing education and knowledge update training can't reconcile with the rapid development of library science and knowledge updating. Previous knowledge storage is too far away from meeting the demand of digitized and networked libraries, let alone university teaching and research in-depth information service.

\section{HOW TO DO WeLl THE CONSTRUCTION OF TALENT} POOL

\section{A. Update Ideas}

"Establishing the library with the purpose of service", "talents boosting the library" and "technology making the library powerful” are three major development strategies which the National Library came up with in Eleven Five Plan. Talent is the basis, technology the means, and services the purpose. This sufficiently shows that talents have become the strategic resource of library's development nowadays and the key factor of fostering undertakings' progress. So setting a correct outlook on talents, setting talents-oriented ideas, and regarding the exploitation of Human resources as a longterm development goal have been put on agenda. We must realize that talent is the resources to develop, talent is the capital to operate, talent is the asset to value, and talent is the capital to flow[4]. As an old saying goes, "the length of a country's prosperity lies in its justice; the prosperity of the politics lies in its popularity.” In the informational and digital days, the competition of society, science and culture is the competition of talent in the final analysis. American libraries attach great importance to personnel training. Early in 1970, ALA put forward the human development policy, particularly explaining that "as long as the education received is good for the work undertaken, it's fine to be in any form, among which is creating the continuing education conditions for librarians". The development of university library is inseparable from talent pool. Who has the talent holds the superiority of development and can remain invincible in the fierce competition.

\section{B. Establish Scientific and Standard Personnel System}

\section{1) Establish the reasonable access system}

The introduction of talent ought to make for accomplishing the goal of library construction and development. Posts are to be set to their needs and determine people. So University Library should establish a scientific talent selection mechanism and a unified selection criterion, and introduce an open competition mechanism to provide objective scientific basis for reasonable talent introduction according to their own needs. In the process of introducing the requisite talents in library, blind introduction of highly educated personnel should be avoided and the knowledge structure of talents is supposed to meet and promote the development of library. To establish a reasonable access system is helpful to improve the comprehensive quality of librarians in universities and improve the service level of library and social status.

\section{2) Formulate a scientific evaluation system}

Based on the scientific evaluation system, the library can give full scope to the talents and people can make the best use of the library. It also plays the role of incentives to the librarians to improve their professional levels to adapt to the requirements of position that the talent competition mechanism of survival of the fittest is strengthened and that the talent evaluation system of appointment is implemented to make cadres ready to take a lower post as well as a higher one. Talent assessment and reward and punishment should be objective and fair to develop talents evaluation mechanism of justice. Establish the scientific system of performance evaluation, and strengthen the training and development of human resources. Scientific appraisal system requires us to seriously study and formulate the development strategy consistent with economic requirements of the times, and to innovate human resources management, founding a corresponding new model of human resource management and strengthening librarians' self-improvement.

3) Implement effective management system

To begin with, it is a must for the university libraries to establish the flowing mechanism of talents within the university libraries, promoting talents' rational and orderly flow of the internal, to actualize the effective talent management system. Reasonable flow of talent helps to optimize the allocation of talent, making talents to achieve 
value-added in optimization and giving full play to the librarians' personal potentials.

Establish competitive position and rotation system. Secondly, university library can provide a channel for a display of the librarians' characteristics, expertise as well as for itself a selection of talent and preferred employment through competitive position, helping excellent talents to get key positions through the competition; competitive position creates an open, just, and fair environment for talent development, truly reflects the "people-oriented" purpose in the development of human resources and realize the flexible management of organization. Through the cycle of rotation, not only can the labor intensity within positions be effectively averaged, but also it's contributive to the cultivation of compound talents.

\section{Construction Personnel of Adapting to the Needs of Library Development}

With the development of society and the advance of technology, we have ushered in the digital age. Library automation degree has risen generally, and the library has undergone great changes in the resource organization form, service concept, service content, and service means, so a crew of personnel is required to adapt to the needs of library development. In the aspect of the digital resource construction of library, library staff should not only familiarize themselves with the requirements of library business knowledge, but have an intimate knowledge of computer operation, network use. In the reader service, network real-time consultation and subject blog have become new service models. Librarians must change the service idea from passive service to active service, be familiar with the use of various types of database, make comprehensive use of various retrieval functions and fast acquire, transfer the reader the required documents. Library can provide the business backbone in various positions with outgoing learning and exchange opportunities as well as special fund for training to make it the main force of library personnel and core strength through the "going out" and "please coming in" approach. Meanwhile, we can also hire a number of old experts to train oriented professional talents and create learning library to make librarians armed with broad knowledge and pluralistic knowledge structure and good coordination ability[5].

\section{CONCLUSION}

Talents play a decisive role in the survival and development of library. Only when university library attract talents, foster talents and make rational and effective use of personnel to nurture a large number of extraordinary talents, can it achieve long-term development at length. As the digital age has brought challenges and opportunities to the development of the library, it's more urgent for university library to create a crew of compound personnel consisting of the business backbone and subject experts of high quality and reasonable structure with multi-disciplinary backgrounds to suit the current development of the informatization, digitization, and networking to promote the sustainable development of library.

\section{REFERENCES}

[1] Wu Jianzhong. New Theory of the 21st Century Library [M]. Shanghai Scientific and Technical Documents Publishing House, in 1998. (In Chineses)

[2] Li Meiying. Brief Analysis of the Construction of Library Personnel [J]. Journal of Agricultural Library and Intelligence, 2011, (8) :223225. (In Chineses)

[3] Huang Weiyu. construction of university library talent pool in digital age [J]. Modern Information, 2008, (3):135-136. (In Chineses)

[4] Liu Fanru, Chen Hongmei. On the construction of university library talent pool [J]. University Library and Intelligence Sciences, 2004, 22(2): 27-29. (In Chineses)

[5] Shan Yong. Discussion on what libraries in China can learn from Foreign Library Personnel Training [J]. Modern Information, 2003, (9): 36-37. (In Chineses) 